\title{
Evaluation of the Oedometer Tests of Municipal Landfill Waste Material
}

\author{
Emőke Imre' ${ }^{1}$, Tibor Firgi ${ }^{1}$ and Gábor Telekes ${ }^{1}$ \\ ${ }^{1}$ Institute of Civil Engineering, Ybl Miklós Faculty of Architecture and Civil Engineering, \\ Szent István University, Budapest, Hungary \\ emoke.imre@ybl.szie.hu ; firgi.tibor@ybl.szie.hu ; telekes.gabor@ybl.szie.hu ;
}

\begin{abstract}
The aim of the ongoing research is (i) to develop a new biodegradation landfill technique so that the landfill gas production could be controlled and the utilisation of the landfill gas could economically be optimized, (ii) to plan the energy utilisation of the landfill including individual and combined solutions (solar, wind, geothermal energy, energy storage using methanol etc.). [1, 2, 3] After summarizing the previous measurements made on the ongoing research, the first results of the oedometer tests are presented. The compression curves were determined, the measured data are evaluated by two simple models, the parameters are identified, the reliability of the parameters is tested.

The simple models make possible the separation of the three major components of the settlement: the immediate settlement, the creep settlement and the primary consolidation settlement. The degradation induced strains were not considered since the tests were short term. Using these components, three different oedometric moduli are defined.

The identified parameters are presented and compared with the parameters previously identified from some CPTu dissipation test data, and with the parameters measured by some recent seismic tests. The parameters are used to estimate the settlement of the landfill.
\end{abstract}

Keywords: landfill, waste material, waste sample, oedometer test, modelling, inverse problem solution, biodegradation.

\section{INTRODUCTION}

\subsection{General}

In the first stage of the research several measurements have been made in relation to the model validation (Figures 1 to 5). In 2006, nearly at the end of the filling period of stage 1 of the Pusztazámor landfill, some surface settlement measuring points were built and measured. Borings with sampling were made, some CPTu probings were made and some geophysical in situ tests (with an FD downhole moisture meter, seismic test) were applied. Using the samples, laboratory tests were made to determine the grading curve, the shear strength of the waste and the $\mathrm{k}$ function of the lower isolation layer of the landfill. In this part of the research the compression tests are going on and the first results are presented. 


\subsection{Oedomertic tests on waste}

Several results are available on the oedometric tests of waste, these papers are partly related to the effect of the unusual material properties on the hydraulic characteristics of the waste and the role of the biological degradation.

In this paper the accent is given on the testing the mechanical properties of the waste in a short term manner. In relation to this two papers are presented. Kavazanjian et al [4] measured the compression of reconstituted waste samples in large scale oedometers from which a clear and consistent difference in elasto-plastic virgin loading and elastic unloading compression coefficients can be observed.

Bjerrum [5] noted that creep produces an increase in the effective preconsolidation pressure, thereby creating a stage of relatively stiff, elastic straining before elasto-plastic virgin compression is regained.

Landva et al [6] applied alternating increments of vertical stress and creep loading to 9 year old partly decomposed waste in large $(450 \mathrm{~mm})$ oedometers. Each of the creep loading stages lasted for a period of one week only so none allowed for much (if any) biodegradation. Their results, indicate a form of visco-elasto-plastic settlement behaviour identical to that proposed by Bjerrum for more conventional soils.

\subsection{Content of paper}

After summarizing the previous measurements made on the ongoing research, the first results of the oedometer tests are presented. The compression curves were determined, the measured data were evaluated by two simple models, the parameters were identified, the reliability of the parameters was tested.

The simple models make possible the separation of the three major components of the settlement: the immediate settlement, the creep settlement and the primary consolidation settlement. The degradation induced strains were not considered since the tests were short term. Using these components, three different oedometric moduli were defined.

The identified parameters were presented and compared with the parameters previously identified from some CPTu dissipation test data, and with the parameters measured by some recent seismic tests. The parameters were used to estimate the settlement of the landfill.

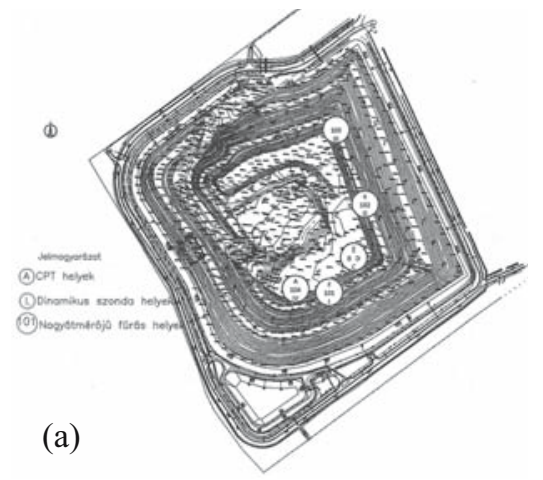

(b)

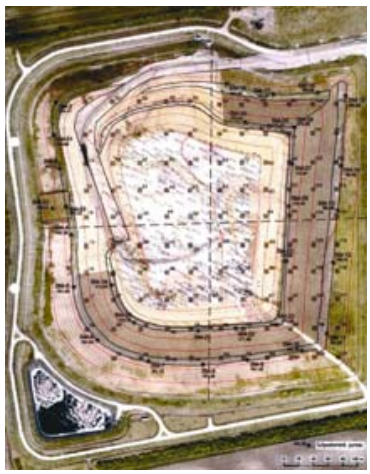

Figure 1. The Pusztazámor landfill site.

(a) Site plane of the first phase with CPTu and boring, (b) Settlement measuring points 


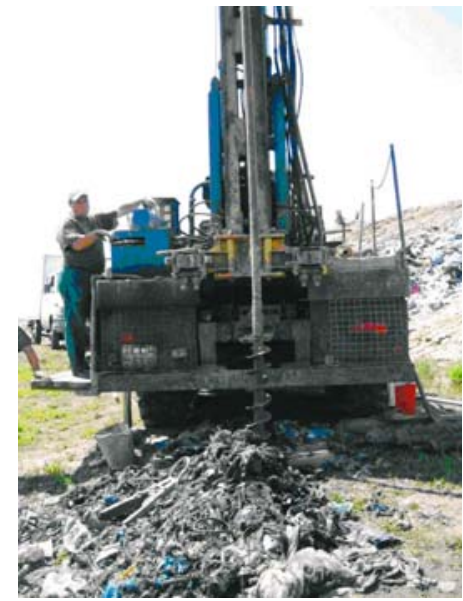

Figure 2. Boring

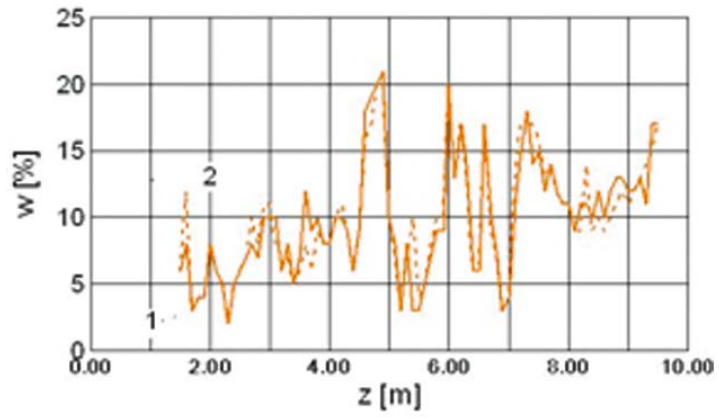

Figure 4. Moisture profile in CPT hole 1.

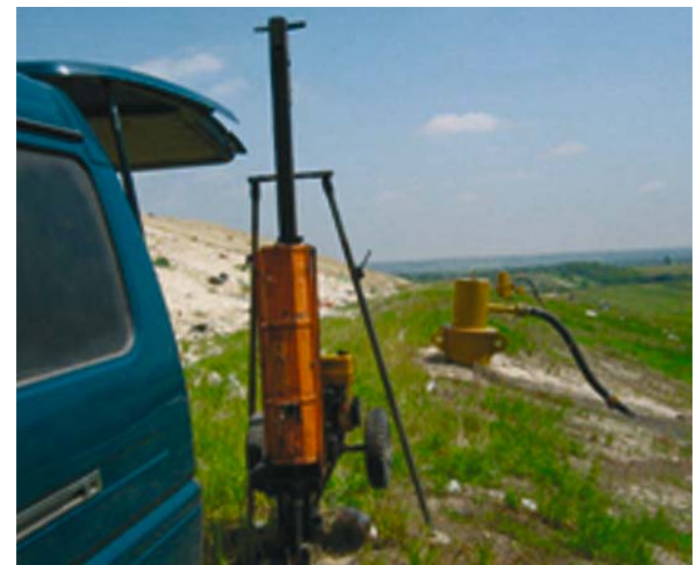

Figure 3. Dynamic probe

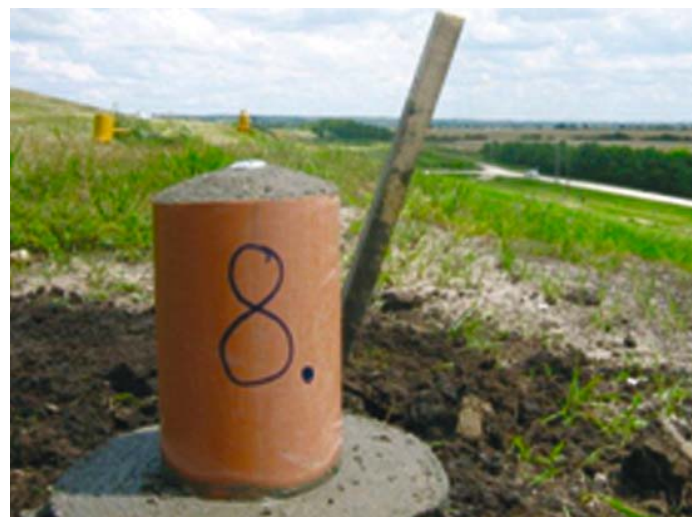

Figure 5. Settlement measuring point.

\section{WASTE EXPLORATION}

\subsection{Types of exploration}

The Pusztazámor landfill site (Figure 1) is built in 3 phases, (in 28 years): the first started to operate in 2000, the second in 2012, and the third one will start to operate in 2025. Each phase is divided into four sections by levees, filling nearly simultaneously, with $55 \mathrm{~m}$ of maximal height.

Some boreholes with large diameter $(180 \mathrm{~mm})$ were made according to (Figure 1) on the landfill, at five places, in $12 \mathrm{~m}$ to $20 \mathrm{~m}$ of depths and 'intact sampling' was made (see Appendix B). The in situ measurements are shown in (Figures 2 to 5).

After some Dynamic Probes, partly two CPTs were made with continuous logging and dissipation tests at various depths. Solid pipes were pushed down into the CPTu holes with a cone at the bottom of the hole. This pipes were of $50 \mathrm{~mm}$ PVC access tubes. 
A customized downhole version of FDR equipment was then used developed by the RISSAC for measuring of landfill moisture content originally developed for soils.

In 2006, nearly at the end of the filling period of stage 1 of the Pusztazámor landfill, some surface settlement measuring points were built and measured. In 2013, at the end of the filling period some seismic tests were made.

\subsection{Characterization of waste}

The waste hill can be decomposed into five layers according to the anaerobic decomposition of organic matter, which can be summarized as follows (Figure 6):

- Phase I (Lag phase). An acclimation period in which moisture starts accumulating and aerobic bacteria begins to consume the oxygen trapped in freshly deposited solid waste.

- Phase II (Transition phase). The first anaerobic phase where total volatile acid (TVA) reaches a detectable level and chemical oxygen demand (COD) increases.

- Phase III (Acid formation phase). The second anaerobic phase is characterized by microbial conversion of biodegradable organic content and the activity of acidogenic bacteria increases.

- Phase IV (Methane fermentation phase). In this phase intermediate acids are consumed by methanogenic bacteria and converted into methane and carbon dioxide.

- Phase V (Maturation phase). A marked drop in landfill gas production.

The evaluation of the results of the borings started with layer identification of waste using the undisturbed samples of the borings, determining the organic content and, biological features.

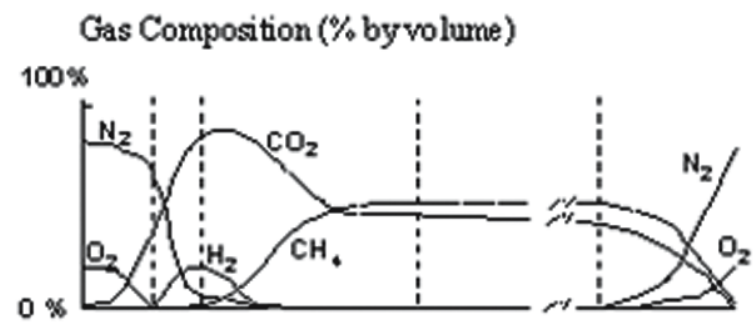

Leachate Concentrations

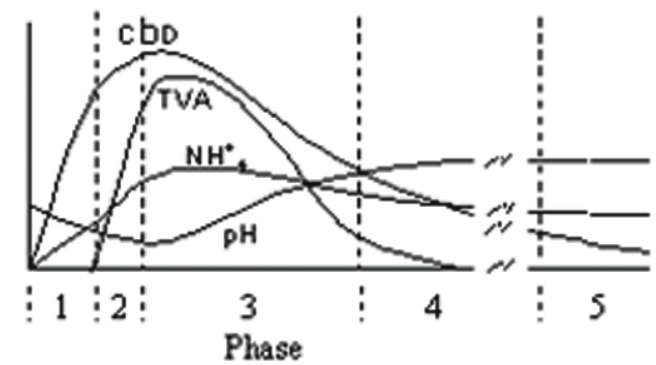

Figure 6. The anaerobic decomposition of organic matter ([9]) 


\begin{tabular}{|c|c|c|c|}
\hline $\begin{array}{c}\text { 1. degradation stage } \\
\text { subsamples }\end{array}$ & A & B & C \\
\hline$\varphi^{\prime}\left({ }^{\circ}\right)$ & 35 & 36 & 35 \\
\hline $\mathrm{c}^{\prime}(\mathrm{kPa})$ & 4 & 26 & 26 \\
\hline $\mathrm{w}(\%)$ & 32 & 36 & 30 \\
\hline Organic content $(\%)$ & 64 & 56 & 50 \\
\hline
\end{tabular}

Table 1(a) Sample properties 1st degradation phase (after [7])

\begin{tabular}{|c|c|c|c|}
\hline $\begin{array}{c}\text { 2. degradation stage } \\
\text { subsamples }\end{array}$ & D & E & F \\
\hline$\varphi^{\prime}\left({ }^{\circ}\right)$ & 27 & 28 & 23 \\
\hline $\mathrm{c}^{\prime}(\mathrm{kPa})$ & 15 & 4 & 22 \\
\hline w $(\%)$ & 46 & 55 & 58 \\
\hline Organic content $(\%)$ & 43 & 41 & 38 \\
\hline
\end{tabular}

Table 1(b) Sample properties 2nd degradation phase (after [7])

\begin{tabular}{|c|c|c|c|}
\hline $\begin{array}{c}\text { 3. degradation stage } \\
\text { subsamples }\end{array}$ & G & H & I \\
\hline$\varphi^{\prime}\left({ }^{\circ}\right)$ & 23 & 22 & 23 \\
\hline $\mathrm{c}^{\prime}(\mathrm{kPa})$ & 13 & 11 & 16 \\
\hline $\mathrm{w}(\%)$ & 89 & 84 & 80 \\
\hline Organic content $(\%)$ & 33 & 36 & 36 \\
\hline
\end{tabular}

Table 1(c) Sample properties 2nd degradation phase (after [7])

\begin{tabular}{|c|c|c|c|}
\hline $\begin{array}{c}\text { 4. degradation stage } \\
\text { subsamples }\end{array}$ & $\mathbf{J}$ & $\mathbf{K}$ & $\mathbf{L}$ \\
\hline$\varphi^{\prime}\left({ }^{\circ}\right)$ & 21 & 22 & 22 \\
\hline c' $(\mathrm{kPa})^{\mathrm{w}(\%)}$ & 12 & 10 & 11 \\
\hline Organic content (\%) & 107 & 96 & 104 \\
\hline
\end{tabular}

Table 1(d) Sample properties 2nd degradation phase (after [7])

\begin{tabular}{|c|c|c|c|}
\hline $\begin{array}{c}\text { 5. degradation stage } \\
\text { subsamples }\end{array}$ & $\mathbf{M}$ & $\mathbf{N}$ & $\mathbf{O}$ \\
\hline$\varphi^{\prime}\left({ }^{\circ}\right)$ & 21 & 20 & 20 \\
\hline $\mathrm{c}^{\prime}(\mathrm{kPa})$ & 5 & 4 & 3 \\
\hline $\mathrm{W}(\%)$ & 121 & 116 & 119 \\
\hline Organic content $(\%)$ & 19 & 24 & 15 \\
\hline
\end{tabular}

Table 1(e) Sample properties 2nd degradation phase (after [7])

\begin{tabular}{|l|c|c|c|c|c|}
\hline $\begin{array}{l}\text { Degradation } \\
\text { phase }\end{array}$ & 1. & 2. & 3. & 4. & 5. \\
\hline $\begin{array}{l}\text { Coarse fraction } \\
(\%)\end{array}$ & $66-86$ & $58-75$ & $40-58$ & $30-45$ & $25-40$ \\
\hline $\begin{array}{l}\text { Sand fraction } \\
(\%)\end{array}$ & $10-25$ & $11-27$ & $20-35$ & $20-35$ & $20-35$ \\
\hline $\begin{array}{l}\text { Fine fraction } \\
(\%)\end{array}$ & $5-15$ & $8-18$ & $15-30$ & $25-40$ & $35-50$ \\
\hline
\end{tabular}

Table 2 Grading test results (after [7]) 


\subsection{Previous laboratory test results in this research}

Concerning the undisturbed landfill samples, the $16 \mathrm{~mm}>\mathrm{d}$ part was separated which is a soil like material and the $\mathrm{d}>16 \mathrm{~mm}$ part - which can be classified according to its constituent material (plastic, textile, metal, paper, wood, gravel, glass, organic) - was discarded for the laboratory tests (Tables 1 to 2, [7],[10] ).

Table 1 summarizes layer characteristics and the shear strength test results. With the advancement of degradation internal friction of waste greatly decreases, while the cohesion of waste decreases less significantly (Figure 7).

(Table 2) depicts soil fractions as a function of degradation. The ratio of coarse grained soils decreased by more than $50 \%$, while the ratio of fine grained soils increased fivefold. The ratio of sand was between $16-26 \%$.

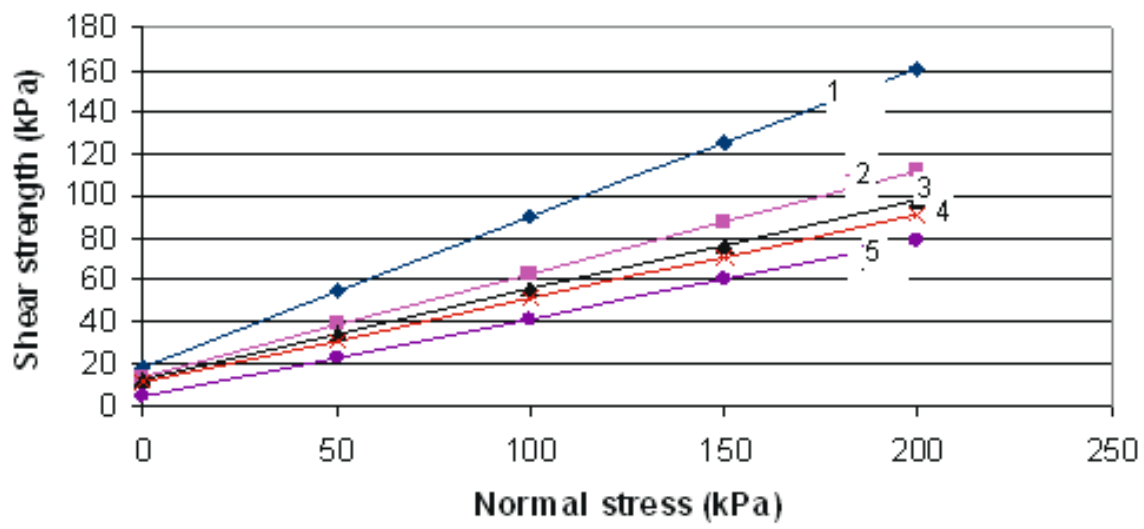

Figure 7. Shear strength results for degradation phase 1 to 5 (after [7])

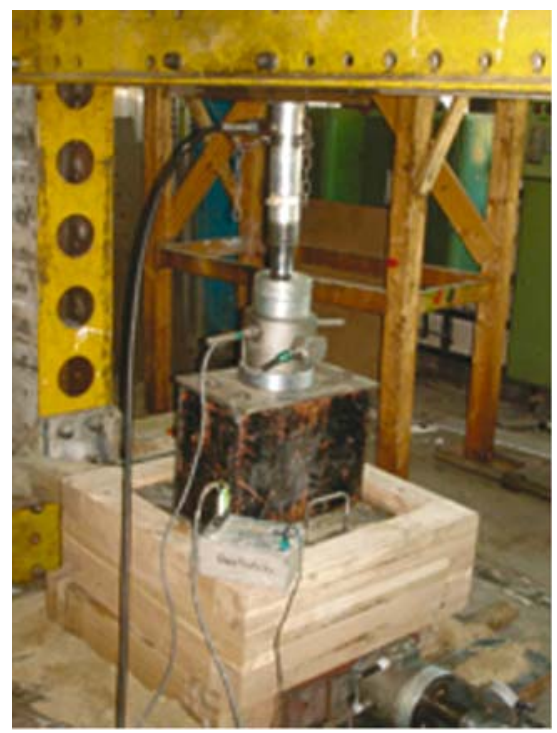

Figure 8. Direct shear test for waste (after [7]) 


\subsection{Previous in situ test results in this research}

Using the continuous and the dissipation type CPTu probes, the waste was explored. Moreover, the boreholes were used for other in situ measurements as well. Then the average value and the standard deviation of the cone resistance were determined for all layers (Figure 9).

The non-monotonic dissipation test data were evaluated using a mathematically precise method ([11], see Appendix B), including a coupled consolidation model, assuming nonmonotonic initial condition and a gradient-free, automatic, non-linear, inverse problem solver.

The results concerning the model fitting are shown in (Figure 10), the coefficient of consolidation is shown (Table 3.) [8].

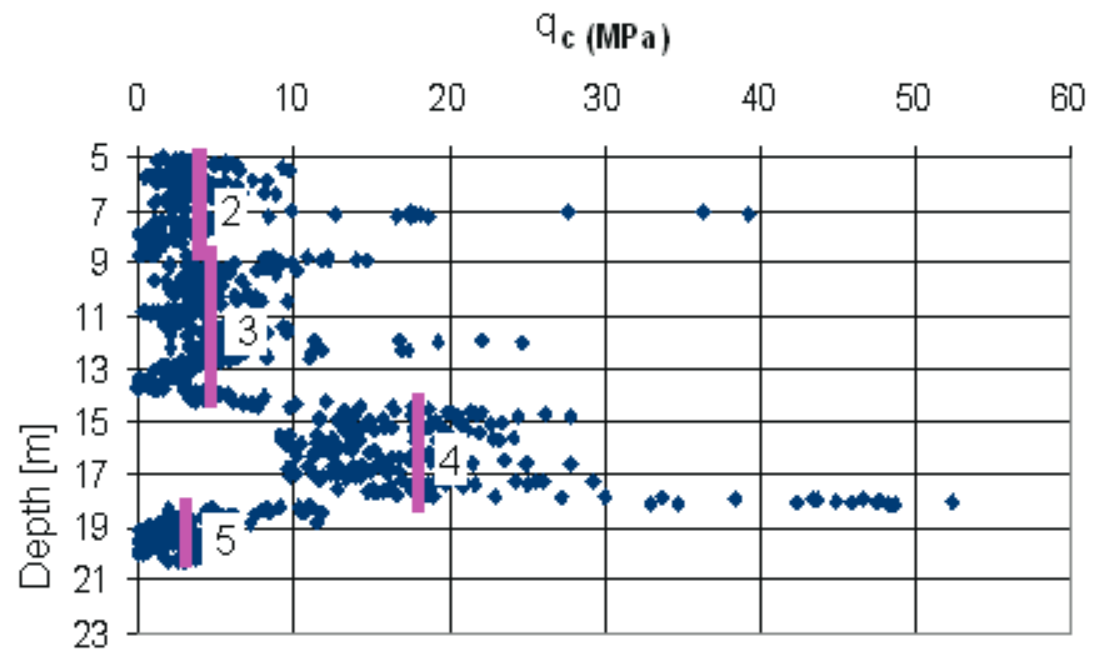

Figure 9. CPT data for layers 2 to 5 (after [7])

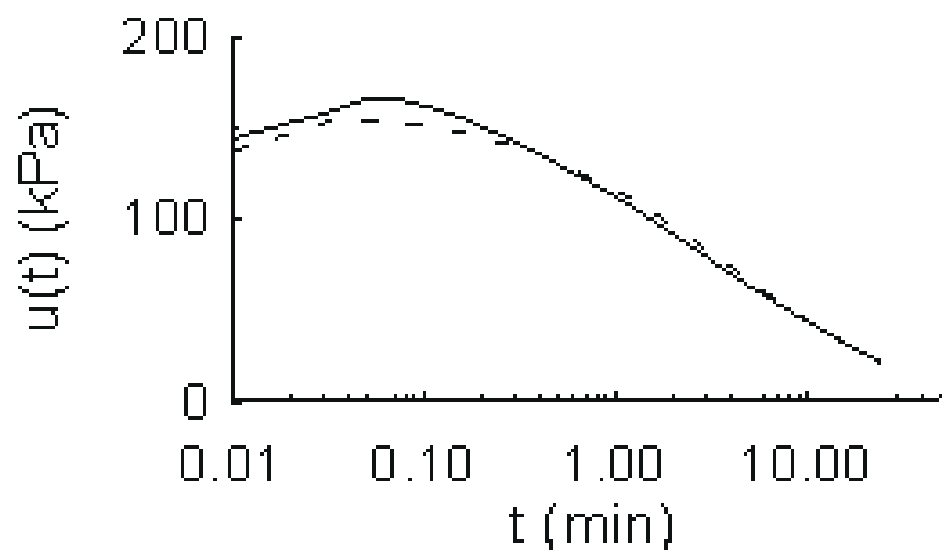

Figure 10. Typical measured (continuous line) and fitted (dashed line) dissipation curves (after [12]). 


\begin{tabular}{|r|r|r|r|r|}
\hline $\begin{array}{r}\text { Dissipation } \\
\text { test }\end{array}$ & $\begin{array}{r}\text { Depth } \\
{[\mathrm{m}]}\end{array}$ & $\begin{array}{r}\text { Degradation } \\
\text { phase }\end{array}$ & $\mathrm{u}_{0}[\mathrm{kPa}]$ & $\mathrm{c}\left[\mathrm{m}^{2} / \mathrm{s}\right]$ \\
\hline 1 & 19 & 5 & 20 & $5,00 \mathrm{E}-06$ \\
\hline 1 & 19 & 5 & 180 & $3,00 \mathrm{E}-06$ \\
\hline 2 & 19 & 5 & 180 & $9,00 \mathrm{E}-07$ \\
\hline 7 & 8 & 2 to 3 & 0 & $1,00 \mathrm{E}-06$ \\
\hline
\end{tabular}

Table 3. Identified coefficient of consolidation $\mathrm{c}$

\begin{tabular}{|c|c|c|c|r|r|}
\hline No & $h(\mathrm{~m})$ & $z(\mathrm{~m})$ & $v_{\mathrm{s}}(\mathrm{m} / \mathrm{s})$ & $\rho(\mathrm{g} / \mathrm{cm} 3)$ & $G_{0}(\mathrm{MPa})$ \\
\hline 1 & 1,5 & 1,5 & 126 & 1 & 16 \\
\hline 2 & 0,3 & 1,8 & 120 & 1 & 14 \\
\hline 3 & 0,3 & 2,1 & 118 & 1 & 14 \\
\hline 4 & 0,4 & 2,6 & 115 & 1 & 13 \\
\hline 5 & 0,7 & 3,2 & 113 & 1 & 13 \\
\hline 6 & 0,4 & 3,6 & 110 & 1 & 12 \\
\hline 7 & 0,6 & 4,3 & 110 & 1 & 12 \\
\hline 8 & 0,7 & 5 & 108 & 1 & 12 \\
\hline 9 & 1 & 6 & 107 & 1 & 11 \\
\hline 10 & 1,3 & 7,3 & 106 & 1 & 11 \\
\hline 11 & 2,1 & 9,4 & 109 & 1 & 12 \\
\hline 12 & 3,7 & 13,1 & 116 & 1 & 13 \\
\hline 13 & 3,7 & 16,8 & 144 & 1 & 21 \\
\hline
\end{tabular}

Table 4 Some seismic test results for degradation phase 2 (after [7], [8])

\section{COMPRESSION TESTS}

\subsection{Test methods}

The conventional multistage compression test is generally used for the determination of the compression curve and the coefficient of consolidation. According to the standard ASTM D2435-90, the load increment is less than or equal to the previous load, the duration of the stages is longer than the $99 \%$ of the consolidation time.

The short compression applied here is basically the same as the standard compression tests and can be summarized as follows (see Tables 5 to 7, Figures 11 to 12). The same device was used as for the direct shear tests [7] after some significant modification in the Geotechnical Laboratory of the Szent István University, Ybl Miklós Faculty of Architecture and Civil Engineering (see Figure 11).

The oedometer tests were performed in a $50 \mathrm{~cm} \mathrm{x} 50 \mathrm{~cm}$ box (with sample height of about 7 $\mathrm{cm}$, box height of $40 \mathrm{~cm}$, in a single-drained mode since the drainage was made at the sample bottom only). A hydraulic load system was added, axial and lateral stress measurement and settlement devices were installed, the load, the settlement and the lateral stress were measured. The maximum load is $15 \mathrm{t}$ of the hydraulic system. The displacement and the lateral pressure are measured. The load regime is shown in (Table 7). 


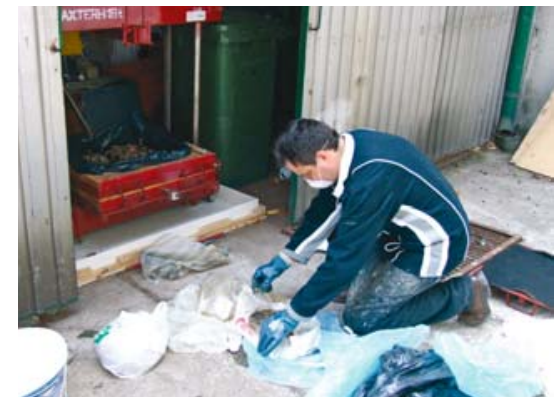

(a) Sample composed from undisturbed waste samples (Table 5).

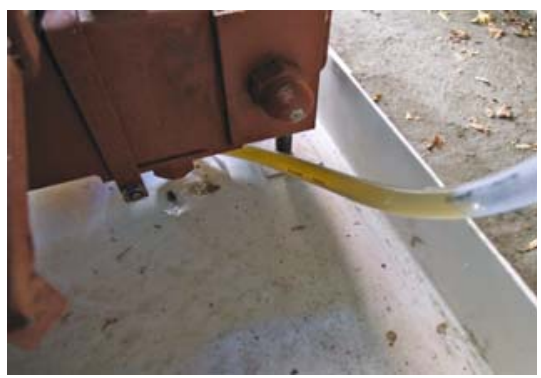

(c) The drainage tube

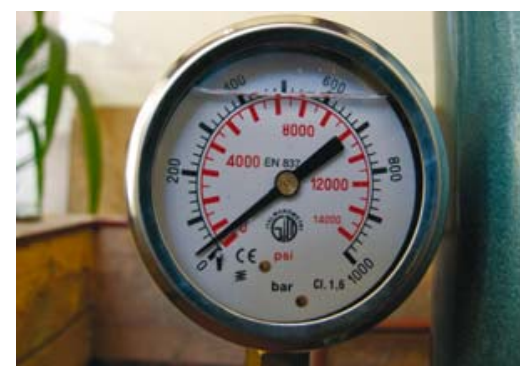

(e) the vertical stress measuring gauges

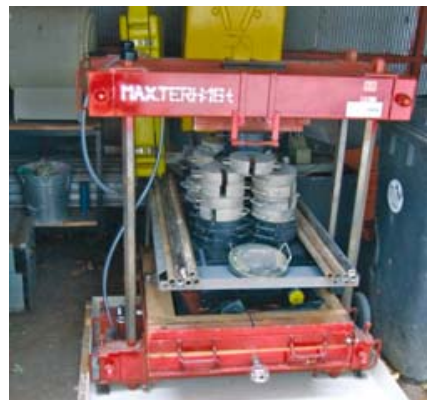

(b) The small loads

(large loads were added hydraulically).

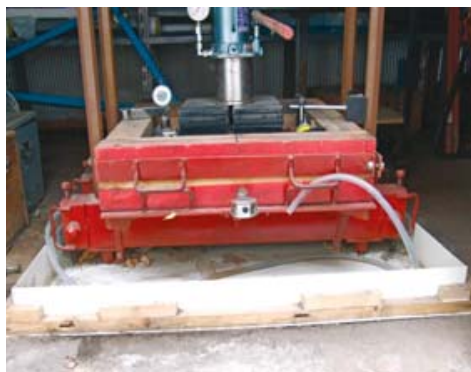

(d) The lateral stress measuring gauge,

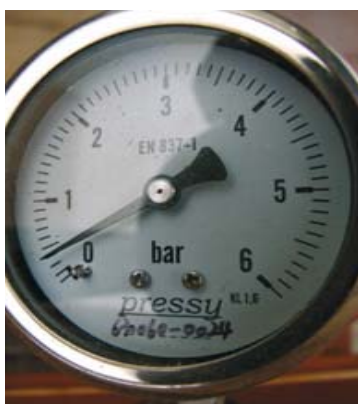

(f) the lateral stress measuring gauges

Figure 11. Compression test

\subsection{Samples}

The undisturbed waste samples with degradation phases 1 to 3 were slightly reconstituted for the testing removing the larges, unifying several samples to create a compression test sample (see Table 5). The physical properties of the waste samples are shown in (Table 6).

In addition, as a comparison, some clay and silt soils from the Great Hungarian Plain - the largest Neogene Depression of the Carpathian Basin filled up with Quaternary deposits - were considered. The samples are originated from Szeged area, from a deepest point of the environment, with locally saline-like spots [13, 17 to 19]. Some standard compression tests were made on these soils and, the results were evaluated with identical models.

For the latter the conventional double-drained multistage compression test equipment was used where the load imposition was instantaneous and was doubled for the standard tests. The displacement was 'hand-recorded'. 


\begin{tabular}{|l|l|l|}
\hline Sample & $\begin{array}{l}\text { Degradation } \\
\text { phase }\end{array}$ & $\begin{array}{l}\text { Composition of samples } \\
\text { Boring number /sampling depth }\end{array}$ \\
\hline 1 & 2 nd & $\begin{array}{l}103 \mathrm{~F} / 0,50,1,00,1,50,2,00 \mathrm{~m} \\
104 \mathrm{~F} / 0,50,1,00,1,50,2,00 \mathrm{~m}\end{array}$ \\
\hline 2 & $3 \mathrm{rd}$ & $\begin{array}{l}103 \mathrm{~F} / 2,50,3,50,4,50,5,50 \mathrm{~m} \\
104 \mathrm{~F} / 2,50,3,00,4,50,5,50 \mathrm{~m}\end{array}$ \\
\hline 3 & $3 \mathrm{rd}$ & $\begin{array}{l}103 \mathrm{~F} / 6,50,7,50,8,50,9,50, \\
10,50,11,50 \mathrm{~m}\end{array}$ \\
\hline
\end{tabular}

Table 5. Sample preparation

\begin{tabular}{|l|l|l|l|l|}
\hline Sample & $\begin{array}{l}\text { Degradation } \\
\text { phase }\end{array}$ & $\begin{array}{l}\text { Water } \\
\text { content } \mathrm{w} \\
{[\%]}\end{array}$ & $\begin{array}{l}\text { Organic } \\
\text { content } \\
{[\%]}\end{array}$ & $\begin{array}{l}\text { Unit } \\
\text { weight } \\
{\left[\mathrm{kN} / \mathrm{m}^{3}\right]}\end{array}$ \\
\hline 1 & 2nd & $\begin{array}{l}45.6- \\
57.8\end{array}$ & $\begin{array}{l}37.5- \\
42.5\end{array}$ & $\begin{array}{l}8.50- \\
9.11\end{array}$ \\
\hline 2 & $3 \mathrm{rd}$ & $79.6-88$. & $32.6-$ & $9.23-$ \\
& & 35.9 & 9.85 \\
\hline 3 & $3 \mathrm{rd}$ & $95.7-$ & $25.6-$ & $10.11-$ \\
& & 106.7 & 29.4 & 10.31 \\
\hline
\end{tabular}

Table 6. Waste parameters (after [7])

\subsection{Test results}

(Figure 12) presents the measured compression curves, comparing them to the compression curve of a soft sweetwater Szeged clay.

According to the results, the maximum volumetric strain for the waste samples is equal to $44 \%, 54 \%, 61 \%$ for samples 3, 2 and 1, respectively. As a comparison, for a soft, lacustrine Szeged clay the maximum strain is about equal to $10 \%$. This result shows that the compressibility of a waste is significantly different than the one of a soil.

As a comparison, in the oedometer tests of Kavazanjian [4] the maximum volumetric strain was less than $40 \%$ and the samples had a marked preconsolidation pressure.

The decreasing compressibility of a waste with increasing degradation phase indicates that the waste is not significantly influenced by its decomposition phase, rather it seems to be influenced by the pre-consolidation stress.

It can be noted that the oedometer tests of the municipal solid waste was made with lateral stress measurement. The lateral stress decreased with time during each stage. The results will be published later on.

\begin{tabular}{|c|c|c|c|}
\hline Stage & Load $[\mathrm{kPa}]$ & Stage & Load $[\mathrm{kPa}]$ \\
\hline 1 & 5 & 5 & 80 \\
\hline 2 & 10 & 6 & 160 \\
\hline 3 & 20 & 7 & 320 \\
\hline 4 & 40 & 8 & 640 \\
\hline
\end{tabular}

Table 7. Load regime 

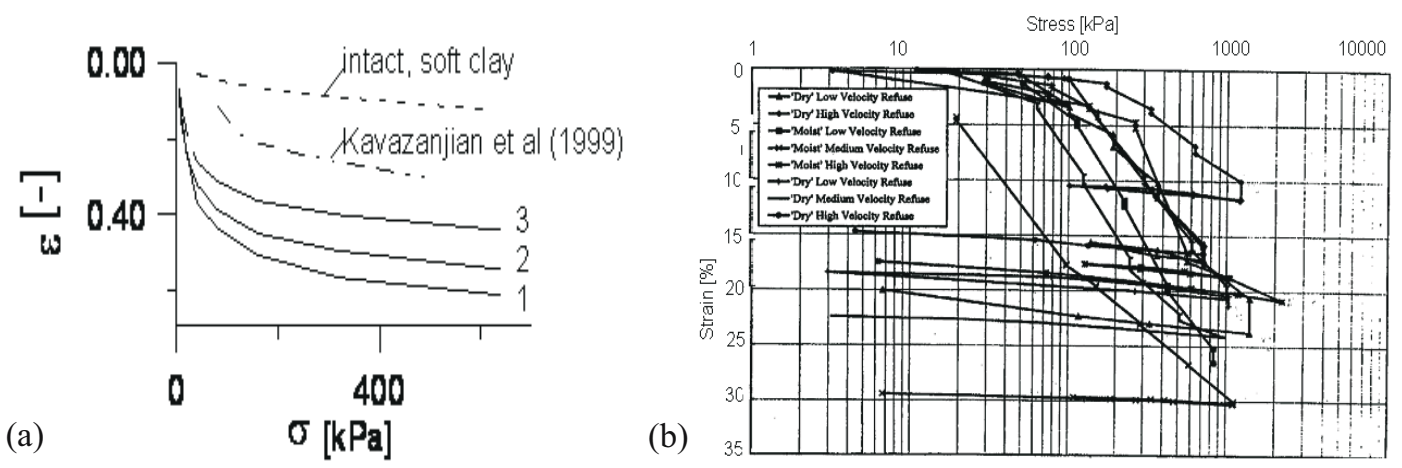

Figure 12. (a) Compression curves, result of samples 1, 2, 3 with degradation phase of 1, 2, 3. in semi-logarithmic plot. (b) Kavazanjian [4]

\section{EVALUATION OF COMPRESSION TEST RESULTS}

\subsection{Modelling}

The stages of the moist sample 3 (being in the capillary zone of the leachate) were evaluated by the modified Terzaghi's (A) and, the modified Bjerrum's (AC) models [13].

The suggested model AC consists of a linear, saturated, coupled consolidation partmodel and an empirical creep part-model, which are superimposed. A term for the immediate compression is included. The suggested model A consists of a linear, saturated, coupled consolidation part-model and a term for the immediate compression is included.

These models differ significantly from the original models since a parameter for the immediate settlement is included in both cases. The displacement of the sample top for model A:

$$
\mathrm{v}(\mathrm{t})=\mathrm{v}_{0}+\mathrm{v}_{1}(\mathrm{t})
$$

and, model AC:

$$
v(t)=v_{0}+v_{I}(t)+v_{2}(t)
$$

where :

$\mathrm{v}_{0}$ is the immediate compression settlement, $\mathrm{v}_{1}$ is the primary consolidation settlement:

$$
\begin{aligned}
& v_{I}\left(c_{v}, t\right)=v_{I, \infty}\left[1-\int_{0}^{2 H} \frac{u\left(c_{v}, t, x\right) d x}{2 H \sigma}\right] \\
& v_{l, \infty}=2 H \sigma / E_{S}
\end{aligned}
$$

$\mathrm{H}$ is the height of the sample, model constant; $\sigma$ is the total stress increment, $\mathrm{E}_{\mathrm{s}}$ is the oedometric modulus, $\mathrm{u}$ is the pore water pressure solution of the Terzaghi's model depending on the coefficient of consolidation $\mathrm{c}_{\mathrm{v}}, \mathrm{t}$ is time, $\mathrm{x}$ is the space variable, $\mathrm{v}_{2}$ is the creep settlement:

$v_{2}(t)=C_{\alpha} \frac{2 H}{1+e_{0}} \log \frac{t+t_{0}}{t_{0}}$

where

$C_{\alpha}$ is the coefficient of creep, $t_{0}$ is time parameter. 


\subsection{Inverse problem solution results}

The methods are described in Appendix B. Since the merit function is practically not sensitive to the variation of parameter $t_{p}$, not every parameter was identified (Table 8 ). Out of the identified parameters only the coefficient of consolidation $c_{v}$ was non-linearly dependent.

The merit function was explored in 50 values of $c_{v}$. The corresponding linearly dependent parameters were determined by the use of the SVD algorithm Press et al [14] in the frame of the sub-minimisation. Then, a function value evaluation was made in each point. The geometry of the merit function was tested by the representation of the minimal section of the merit function concerning parameter $c_{v}$ determined by the software elaborated for the research.

The results of the parameter identification can be seen in (Tables 9 to 10, Figures 13 to 15). According to the results, a single global minimum was found, the solution of the inverse problem was generally unique (Figure 13).

The identified coefficient of consolidation $c_{v}$ varied between $2,45 \mathrm{E}-08$ to $6 \mathrm{E}-08 \mathrm{~m}^{2} / \mathrm{s}$, the triple ratio of the creep - immediate - primary consolidation settlement of the waste was 48:36:16 (model AC), the ratio immediate : primary consolidation settlement of the waste was 49:51 (model A, see Table 9). The coefficient of creep $\mathrm{C}_{\alpha}$ was identified by assuming an arbitrary value for the void ratio, its value was slightly larger than the values identified for the Szeged soils.

The mean coefficient of variation of the identified coefficient of consolidation $c_{v}$ was equal to $66-73 \%$, the mean coefficient of variation of the identified settlement parameters was $7-25 \%$, the mean coefficient of variation of the coefficient of creep was about equal to $12 \%$ (Table 10).

According to (Figures 14 to 15), the immediate compression was significant for small loads, the creep was significant for medium loads. At large loads the strain increment during the stage was considerably less than at medium or small loads.

\begin{tabular}{|l|l|l|}
\hline & Dependence & Parameter \\
\hline$v_{0}$ & Linear & immediate compression \\
\hline$v_{1}$ & Linear & $\begin{array}{l}\text { primary consolidation } \\
\text { settlement }\end{array}$ \\
\hline$c_{\mathrm{V}}$ & non-linear & coefficient of consolidation \\
\hline$C_{\alpha}$ & Linear & coefficient of creep \\
\hline \multicolumn{2}{|c|}{ Table 8. Model parameters } \\
\hline
\end{tabular}

\begin{tabular}{|c|c|c|c|c|c|}
\hline & \multicolumn{2}{|c|}{ model A } & \multicolumn{3}{c|}{ model AC } \\
\hline Stage & Immediate & primary & creep & immediate & primary \\
\hline & $v_{0} / v$ & $v_{1} / \mathrm{v}$ & $v_{2} / v$ & $v_{0} / v$ & $v_{1} / \mathrm{v}$ \\
\hline 1 & 0,64 & 0,36 & 0,13 & 0,61 & 0,26 \\
\hline 2 & 0,35 & 0,65 & 0,16 & 0,31 & 0,53 \\
\hline 4 & 0,54 & 0,46 & 0,42 & 0,43 & 0,15 \\
\hline 5 & 0,40 & 0,60 & 0,65 & 0,24 & 0,11 \\
\hline 6 & 0,48 & 0,52 & 0,51 & 0,33 & 0,16 \\
\hline 8 & 0,53 & 0,47 & 0,35 & 0,45 & 0,2 \\
\hline Mean & 0,49 & 0,52 & 0,48 & 0,36 & 0,16 \\
\hline
\end{tabular}




\begin{tabular}{|r|r|r|r|r|}
\hline stage & $c_{v}$ & $v_{1}$ & $v_{0}$ & $\mathrm{C}_{\alpha}$ \\
\hline Mean for model A & 0,659 & 0,144 & 0,106 & \\
\hline Mean for model AC & 0,725 & 0,247 & 0,065 & 0,118 \\
\hline
\end{tabular}

Table 10. Relative standard deviations (coefficient of variation) $\mathrm{D}(\mathrm{pi}) / \mathrm{pi}$ for the identified parameters, 3rd waste sample

\begin{tabular}{|c|c|c|c|c|c|c|c|}
\hline $\begin{array}{c}\text { Layer } \\
\text { of 10m }\end{array}$ & $\sigma[\mathrm{kPa}]$ & $\varepsilon[-]$ & $\begin{array}{c}\text { settlement } \\
v[\mathrm{~m}]\end{array}$ & $\begin{array}{c}\text { Layer } \\
\text { of 10m }\end{array}$ & $\sigma[\mathrm{kPa}]$ & $\varepsilon[-]$ & settlement $v[\mathrm{~m}]$ \\
\hline 1 & 65 & 0,3 & 3 & 4 & 455 & 0,42 & 4,2 \\
\hline 2 & 195 & 0,38 & 3,8 & 5 & 585 & 0,44 & 4,4 \\
\hline 3 & 325 & 0,4 & 4 & 6 & 715 & 0,48 & 4,8 \\
\hline & & & & Total & & & $24,2 \mathrm{~m}$ \\
\hline
\end{tabular}

Table 11. The settlement estimation of the landfill using compression curve of the 3rd sample

\begin{tabular}{|l|c|c|c|c|c|}
\hline & \multicolumn{2}{|c|}{ model A } & \multicolumn{3}{c|}{ model AC } \\
\hline \multicolumn{1}{|c|}{ Stage } & immediate & primary & immediate & creep & Primary \\
\hline & $v_{0} / v$ & $v_{1} / v$ & $v_{0} / v$ & $v_{2} / v$ & $v_{1} / v$ \\
\hline Medium clay & 0.27 & 0.73 & 0.08 & 0.724 & 0.196 \\
\hline Medium clay & 0.28 & 0.72 & 0.12 & 0.651 & 0.229 \\
\hline Medium clay & 0.17 & 0.83 & 0.03 & 0.58 & 0.39 \\
\hline Sandy silt & 0.02 & 0.98 & 0 & 0.512 & 0.488 \\
\hline Sandy silt & 0.02 & 0.98 & 0.01 & 0.826 & 0.164 \\
\hline \multicolumn{1}{|c|}{ Mean } & 0.15 & 0.85 & 0.66 & 0.05 & 0.29 \\
\hline
\end{tabular}

Table 12. The settlement for the Szeged (locally saline) soils.

\begin{tabular}{|l|r|r|r|}
\hline & \multicolumn{1}{|c|}{ immediate } & \multicolumn{1}{c|}{ creep } & \multicolumn{1}{c|}{ Primary } \\
\hline & \multicolumn{1}{|c|}{$v_{0} / v$} & \multicolumn{1}{c|}{$v_{2} / v$} & \multicolumn{1}{c|}{$v_{1} / v$} \\
\hline silt & 0,00 & 0,67 & 0,32 \\
\hline clay & 0,08 & 0,65 & 0,27 \\
\hline waste & 0,36 & 0,48 & 0,16 \\
\hline
\end{tabular}

Table 13. Summary of settlement data, the mean values deduced from Tables 9 and 12

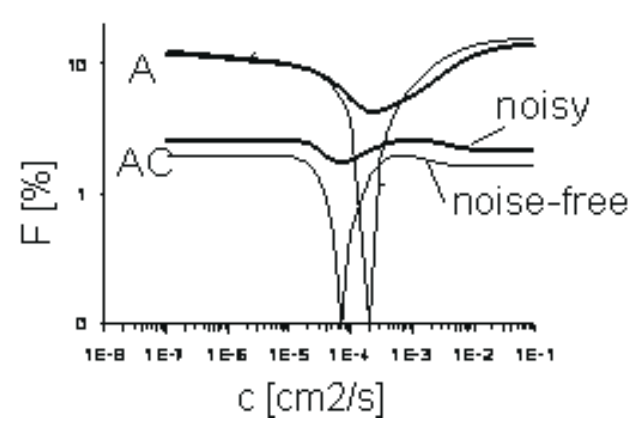

(a) stage 4

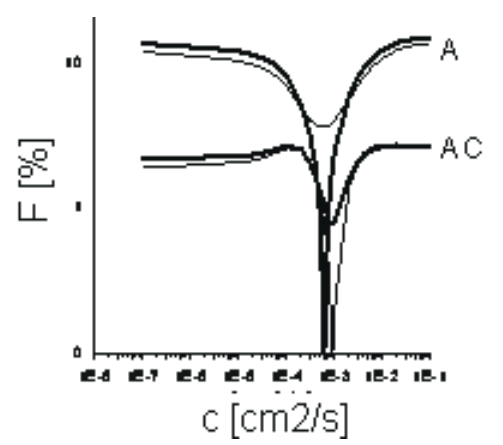

(b) stage 8

Figure 13. The minimal section (CSC) concerning $\mathrm{c}_{\mathrm{v}}$ for models

A and AC, sample 3. Note the single global minimum. 


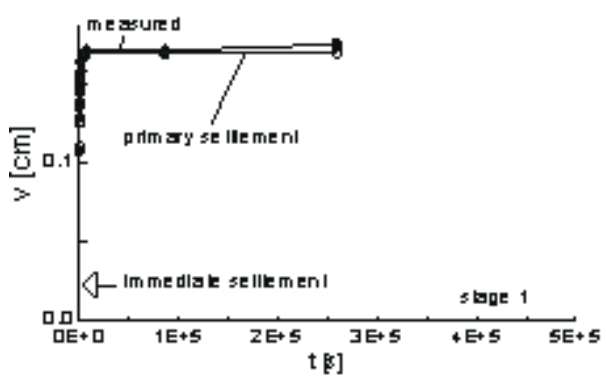

(a) stage 1

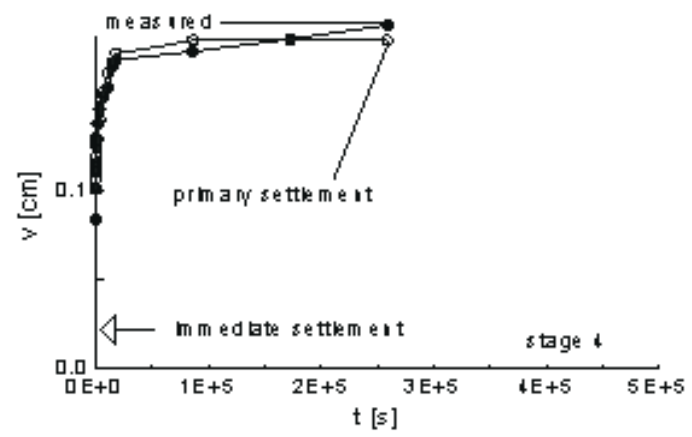

(c) stage 4

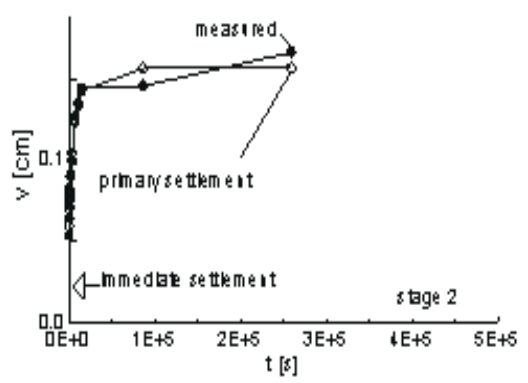

(b) stage 2

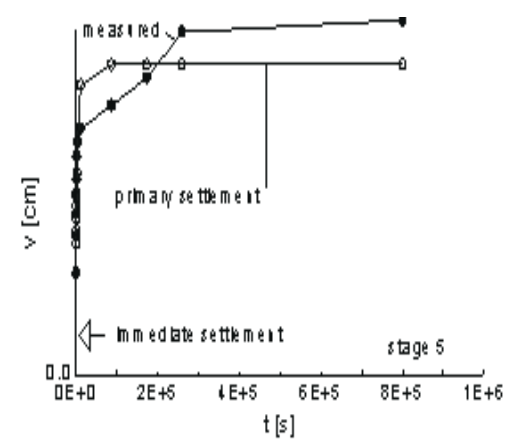

(d) stage 5

Figure 14/a Interpretation of the various stages (1-5) with model A

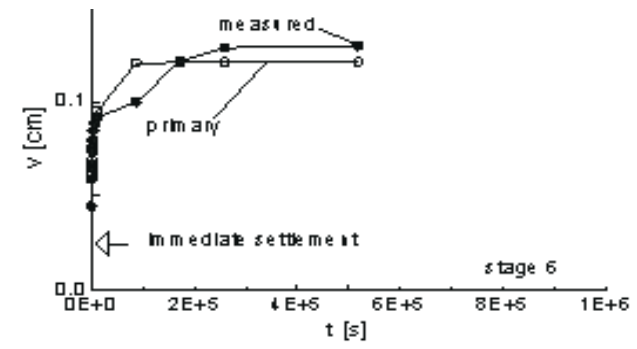

(e) stage 6

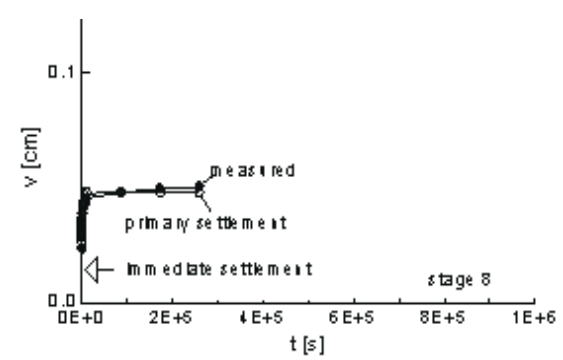

(f) stage 8

Figure 14/b Interpretation of the various stages (6-8) with model A

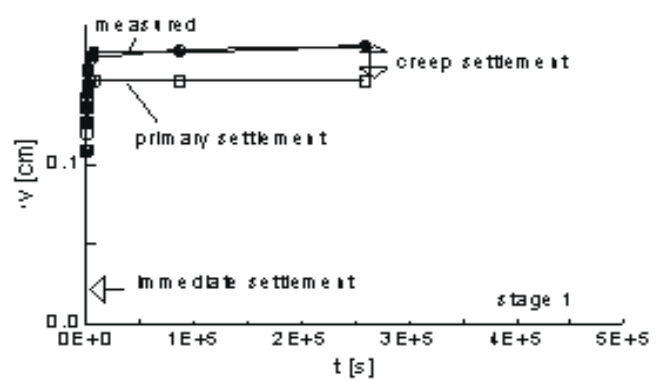

(a) stage

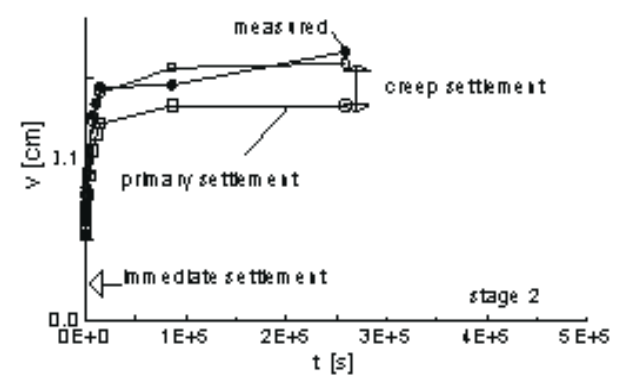

(b) stage 2 


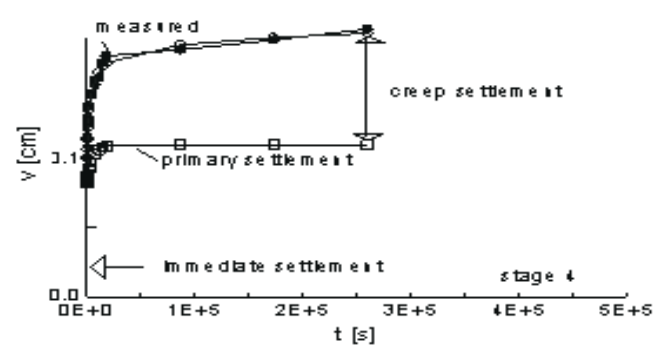

(c) stage 4

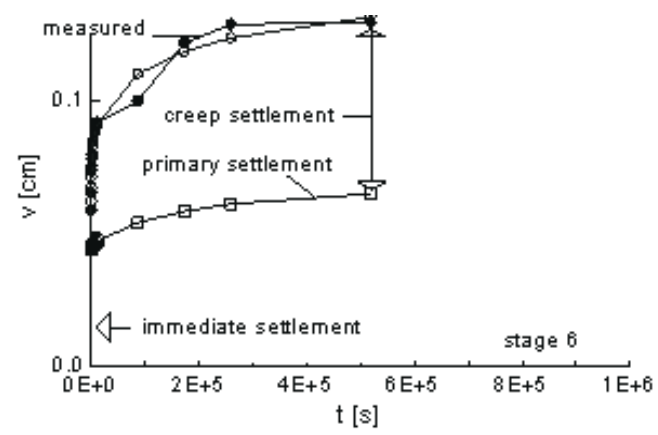

(e) stage 6

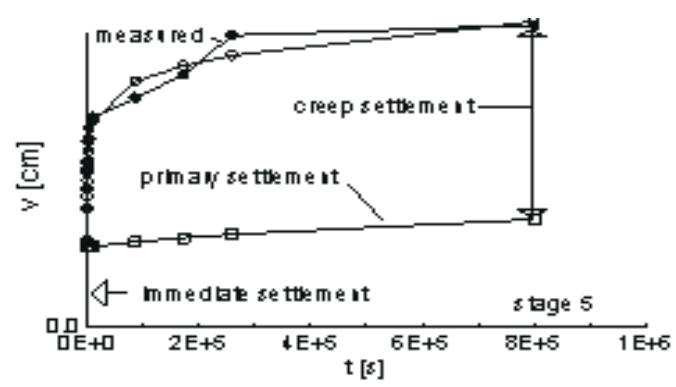

(d) stage 5

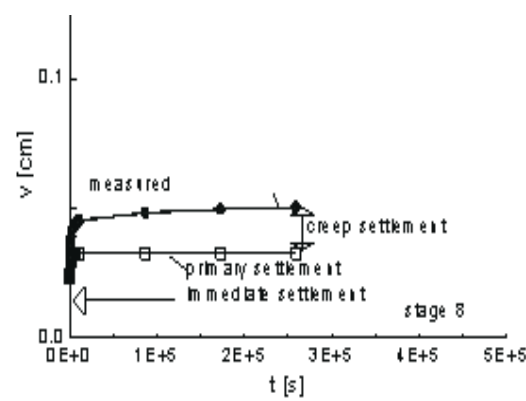

(f) stage 8

Figure 15. Interpretation of the various stages with model AC

\section{DISCUSSION}

\subsection{Models}

The data measured during the stages of moist sample 3 was evaluated using the modified Terzaghi's (A) and the modified Bjerrum model (model AC). In the models a parameter was included for the immediate settlement. The degradation induced strains were not considered since the tests were short term compression tests.

The application of the usual models was supported by the compression test results of previous authors, indicating that a form of visco-elasto-plastic settlement behaviour identical to that proposed by Bjerrum for more conventional soils can be encountered.

\subsection{Evaluation}

The inverse problem solution was generally reliable, a well-defined global minimum of the merit function was found in most cases. This can be explained by the fact that a parameter was included for the immediate settlement $\mathrm{v}_{0}$ taking into account the high compressibility of the waste. The term for the immediate settlement compensated a great part of the non-linearity effects of the waste consolidation. It can be noted that the modified Bjerrum model for normal soils results such merit function that may have multiple minima [15]. 
The error (coefficient of variation) of the identified the coefficient of consolidation $\mathrm{c}_{\mathrm{v}}$ was large (66-73\%) indicating that the linear theory is approximate. The coefficient of variation for the immediate settlement $\mathrm{v}_{0}$ and primary consolidation settlement $\mathrm{v}_{1}$ moreover, for the coefficient of creep $\mathrm{C} \alpha$ was smaller, for the settlement parameters it varied between $7-25 \%$, and for the coefficient of creep it was about $12 \%$.

\subsection{Immediate compression, creep for waste and soils}

The triple settlement ratio immediate:creep:primary for the waste was 36:48:16, for Szeged clay was 8:65:27 and for Szeged silt was 1:67:32 (Tables 9 and 12).

The immediate settlement may be related to the compressibility of the pore fluid if the stage load is small (less than $150 \mathrm{kPa}-200 \mathrm{kPa}$ ) but it is related to the grain compressibility above it.

According to the first results, the immediate settlement is 6 times larger for the waste than for clay, according to the expectations.

It can also be noted that for silt, the immediate compression is negligible or zero. The creep seems to be relatively more important than for the primary consolidation settlement for each tested material (waste, silt or clay).

\subsection{Oedometric moduli deduced by separating the settlement components}

From the identified settlements ones the following oedometric moduli were computed:

$$
E_{s 3}=\frac{2 H \sigma}{v_{0+} v_{1+} v_{2}} E_{s 2}=\frac{2 H \sigma}{v_{1+} v_{2}} E_{s 1}=\frac{2 H \sigma}{v_{1}}
$$

where the first is the usual one, the second modulus does not contain the immediate settlement, the third modulus is related to primary consolidation settlement only. Some seismic tests were made, the results of which can be seen in (Table 4). Using the measured seismic small-strain $G_{0}$ modulus, the approximate degradation values for the shear modulus values estimated from oedometric modulus $E_{s 3}, E_{s 2}$ and $E_{s 1}$ - computed from the results of the model fitting using model AC - were approximately estimated as $0.003,0.03,0.3$, respectively (Figure 16).

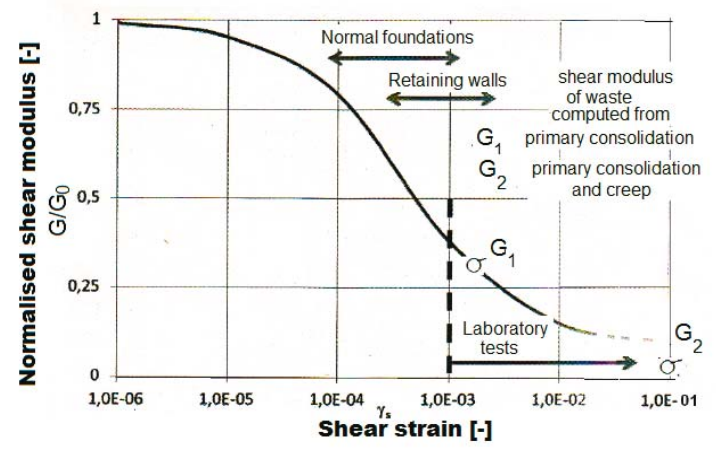

Figure 16. The approximate value of the waste shear modulus $\mathrm{G}_{1}$ and $\mathrm{G}_{2}$ determined from the waste oedometric modulus (computed from the primary consolidation settlement $\left(\mathrm{E}_{1}\right)$ and from the sum of the primary consolidation settlement and the creep settlements $\left(E_{2}\right)$ ) with respect to the small strain shear modulus $G_{0}$ measured by seismic test. $\left(G_{2}, G_{3}\right.$ are too small to illustrate on the figure) 


\subsection{The shear test versus compression test results}

According to the (Figure 7), the shear strength of waste is significantly influenced by its decomposition phase. With the advancement of degradation internal friction of waste greatly decreases, while the cohesion of waste decreases less significantly.

However, according to the Figure 12, the measured compressibility decreases with depth, the compression test results and the direct shear test results have different tendencies with the degree of degradation. The compression curve of sample 3 is stiffer than the one of sample 1, while the shear strength is smaller for sample 3 than for 1 . The first can possibly be explained by the effect of the pre-consolidation stress, the second by the organic decomposition causing the disappearing or the destruction of the bonds.

\subsection{Prediction of the settlement of the landfill}

The mean coefficient of consolidation $\mathrm{c}_{\mathrm{v}}$ identified from the compression test of soil 3 was $2 \mathrm{E}-8$ to $6 \mathrm{E}-8 \mathrm{~m} 2 / \mathrm{s}$ for model $\mathrm{AC}$ and $\mathrm{A}$, respectively, being less than the horizontal, in situ coefficient of consolidation determined by the dissipation test previously as $9 \mathrm{e}-7,1 \mathrm{e}-6 \mathrm{~m}^{2} / \mathrm{s}$. This difference can be attributed to the secondary structure of the waste.

Using the in situ smallest value and of the coefficient of consolidation, the compression curve measured here for sample 3 assuming $1.3 \mathrm{~g} / \mathrm{cm}^{3}$ for the density, the settlement of the Pusztazámor landfill hill with height of about $65 \mathrm{~m}$ originated from immediate compression, creep and primary consolidation in a double-drained mode was estimated as about $25 \mathrm{~m}$ (Table 11) within about 30 years at the $99 \%$ consolidation time:

$$
t=\frac{T H^{2}}{c_{v}}=0,87 / 0,009 \mathrm{~cm} 2 / \mathrm{s} * 3000 \mathrm{~cm} * 3000 \mathrm{~cm}=27,97 \text { year }
$$

This result is a rough estimation since the most important, time dependent settlement components are originated from mostly immediate compression, creep and biodegradation. The time dependency of the creep and primary consolidation is different, the more precise model AC suggests that half of the settlements occurs within a few weeks (Figure 17). The time dependency of the biodegradation is highly dependent on the moisture content of the waste.

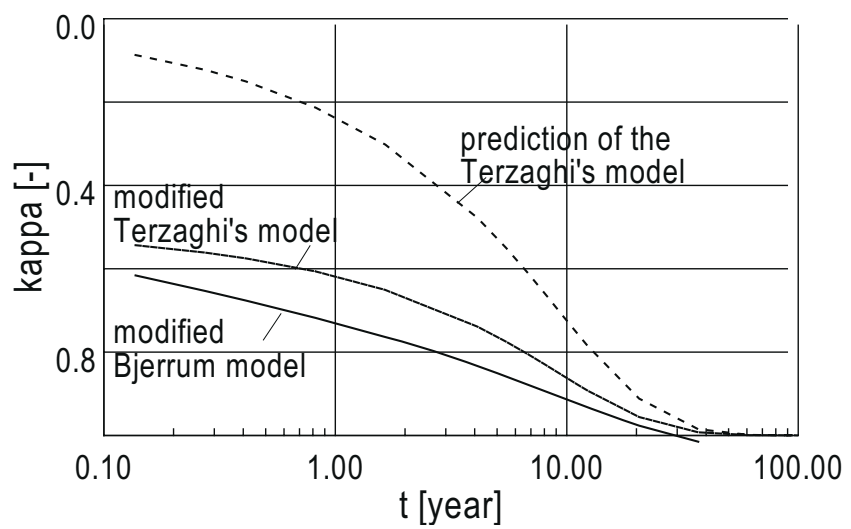

Figure 17. The different time dependency of the self-weight settlement by the various models. 


\section{CONCLUSION}

The first results of the oedometer tests made on some municipal solid waste material (taken at Pusztazámor landfill) with degradation phases 1 to 3 were presented in this paper. The measured data of the moist waste sample with degradation phase 3 was evaluated by some simple models. The results can be summarized as follows.

By comparing the results of the compression tests with literature data, it can be seen that the measured compression curves are in accordance with the results known from the literature except the slightly larger compressibility in the present results. This difference can possibly be attributed to the sample preparation.

By comparing the results of the direct shear tests and the compression curves, it can be seen that the compression test results and the direct shear test results have different tendencies with the phase of degradation. This can possibly be explained by the opposite effect of the preconsolidation stress and the organic decomposition, the latter may cause the destruction of the bonds, the former may cause more compact state.

The evaluation of the compression test results of the moist waste sample with degradation phase 3 was made with simple models. The Terzaghi's (A) and, the Bjerrum's (AC) models were modified such that a term for the immediate settlement was included. The applicability of these models was verified by the previous measurements indicating that the behaviour of the waste and the soil is basically the same during the compression tests. The main results can be summarized and concluded as follows.

1. The coefficient of variation of the identified coefficient of consolidation $c_{v}$ was about is equal to $66-73 \%$. The coefficient of variation of the identified settlement components (immediate, primary, creep consolidation settlement) was considerably less.

2. As a first approximation (Table 13), the identified immediate settlement was $1 \%$ for silt, $8 \%$ for clay and $36 \%$ for waste. The large immediate settlement term was useful to account the non-linearity of the waste consolidation, resulting in unique inverse problem solution.

3. The identified creep settlement was $67 \%$ for silt, $65 \%$ for clay and $48 \%$ for waste. It follows that the creep is the most important component of settlement. Due to the great importance, the creep characteristics need some further research. The identified primary consolidation settlement was $32 \%$ for silt, $27 \%$ for clay and $16 \%$ for waste. It follows that this component has the smallest importance for the waste.

4. By separating the various settlement components, three oedometric moduli Es2 and Es1 could have been defined, using the total settlement, the sum of the creep and primary consolidation settlement and the primary consolidation settlement alone, respectively From the measured seismic small-strain G0 modulus, the approximate degradation values for the shear modulus values related to these oedometric moduli Es3, Es2 and Es1 were computed as $0.003,0.03,0.3$, respectively.

5. The mean coefficient of consolidation $c_{v}$ identified from the compression test of waste sample 3 was smaller by about one order of magnitude than the horizontal, in situ coefficient of consolidation previously determined by the dissipation test. This difference can be attributed to the secondary structure of the waste. 
In future works coefficient of creep $\mathrm{C}_{\alpha}$ will be identified independently of the void ratio, the evaluation results of the remainder samples are discussed, moreover, the parameter identification is extended to some more sophisticated models, for example to the HBM model [16].

\section{REFERENCES}

[1] Imre; McDougall, Farkas, J., Kovács, M., Czap, Z (2003).Bio-Mechanical Research In The Geotechnical Department, Budapest University of Technology and Economics. Res. News of the Budapest University of Technology AND ECONOMICS 1. 33-36.

[2] Imre, E., Trang, P. Q., Laufer, I., Kovács, M, Nédli, P, Firgi, T., Telekes, G. (2009) Inverse problem solution to predict long term behaviour of a landfill using Short term data. Electr. Proc. of Sardinia 2009. 10p.

[3] Kovács, K. L., Bagi, Z., Ács, N., Perei, R. K., Imre, E. Telekes, G, Bartha, I. (2009) Biotechnological methods to increase landfill gas production and degradation of organic Waste. Proc, 3Rd HPM Workshop, Braunschweig, 11тh-12th March 2009. Seite 13, 1-7.

[4] Kavazanjian E., Matasovic N. \& Bachus R. (1999) Large-diameter static and dynamic testing of municipal solid waste. Proceedings Sardinia '99, Seventh International Waste Management and Landfill Symposium, Vol 3, 437-445.

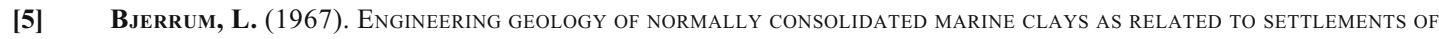
Buildings. Seventh Rankine Lecture. Geotechnique, 16(2): 83-118.

[6] Landva A.O., Valsangar A.J. \& Pelkey S.G. (2000) Lateral earth pressure at rest and compressibility of municipal solid waste. Canadian Geot. J., Vol. 37, 1157-1165

[7] Varga, G (2010): Stability of landfills. PhD Thesis. BME, Budapest, Hungary (in Hungarian)

[8] Törös E. (2006) Critical review of the application of Seismic-Based methods in Civil engineering, PhD Thesis, University of West Hungary, in Hungarian.

[9] Yuen S.T.S (1999) Bioreactor landfills promoted by leachate Recirculation: A full scale study. PhD Thesis, University of Melbourne, Australia.

[10] Varga, G, Imre E, Firgi T, Rajkai K, Czap Z, Telekes G (2011) Laboratory And In Situ Tests of a Landfil. In: Proc. of Fourth International Workshop “Hydro-Physico-Mechanics of Landfills”. Santander, Spain, 2011.04.272011.04.28. PP. 1-10.

[11] Imre, E, Rózsa, P, Bates, L, Fityus, S (2010) Evaluation of monotonous and non-monotonous dissipation test RESUlts. Computers and Geotechnics 37, Pp. 885-904 (Evaluation SOFTWARE : hTtP://PMOKus.gTt.BME.hu)

[12] Imre, E; Firgi, T; Rajkai K; Telekes G; Mile G; Módos J; Subert, I. (2011)Laboratory And In Situ Tests of a Landfil. Proceedings Sardinia 2011, Thirteenth International Waste Management and Landfill . Symposium. Cagliari, Olaszország, 2011.10.03-2011.10.07. PP. 1-12.

[13] Imre, E. (1995). Model discrimination for conventional step-loaded oedometric test. Proc. of the Int. Symp. on Compression and Consolidation of Clayey Soils, IS-Hiroshima'95, 525-530.

[14] Press, W.H.; Flannery, B.P.; Teukolsky, S.A.; Wetterling, W.T. (1986): Numerical Recipes. Cambridge Univ. Press, CAMBRidge

[15] Imre E, Schanz T, Hegedüs Cs. (2013). Some thoughts in non-linear inverse Problem Solution. In: EURO:TUN 2013. Bochum, Németország, 2013.04.17-2013.04.19. Pp. 357-365.

[16] McDougall, J (2007) A hydro-bio-mechanical model for Settlement and other Behaviour in LandFilled Waste Computers and Geotechnics, Volume 34, Issue 4, July 2007, Pages 229-246

[17] Imre E., Firgi, T., Juhász M., Hazay M., Hegedüs M., Bakacsi Zs., Singh V. G. (2014): CPTu pore water pressure Dissipation tests IN SALINE ENVIRONMENT. CPT14 (online)

[18] Imre E., Juhász M., Józsa V., Hegedús M., Bíró B., Singh V. G. (2014) CPTu tests and CPT simple dissipation tests IN SALINE ENVIRONNENT. CPT14 (OMLINE)

[19] Imre E., Schanz T. and Vijay P. Singh (2013) Evaluation of staged oedometric tests 251-268. Proc. Of the 3Rd Kézdi Conference. Budapest, Hungary, ISBN 978-963-313-081-0

\section{ACKNOWLEDgmentS}

The authors thank for the support of the National Research Fund Jedlik Ányos NKFP B1 2006 08, the Norwegian research fund HU-0121 (Seed Money). The suggestions and the help of Balazs Vikker, Borbála Bíró, Ian Fleming, Kornél Kovács and Attila Olgyay-Szabó are greatly acknowledged. 


\begin{tabular}{|l|l|}
\hline Depth $[\mathrm{m}]$ & Name of layer \\
\hline $0,0-0,2$ & fill \\
\hline $0,2-1,6$ & Silty sand \\
\hline $1,6-4,2$ & Waste \\
\hline $4,2-5,1$ & Silty sand \\
\hline $5,1-11,8$ & Waste \\
\hline $11,8-21,1$ & Silty waste \\
\hline note & $\begin{array}{l}\text { After the boring well is made until } 20,75 \mathrm{~m}, \text { using } \\
50 \text { mm access tube }\end{array}$ \\
\hline note & Leachate water at $11,8 \mathrm{~m}$ \\
\hline
\end{tabular}

Table A-1 Profile of a diameter 180mm boring, depth of 21,1 m

\section{APPENDIX 2 INVERSE PROBLEM SOLUTION}

This section presents the method used for the evaluation of the dissipation test and the compression test.

\subsection{Inverse problem solution method}

The aim of the non-linear model fitting is to determine the global minimum of a least squares objective or merit function. Using the classical minimisation methods, a trial and error procedure is needed which ends repetitively in a local minimum from various starting vectors and, finally the smallest one is selected. There is a general observation that in case of real-life inverse problems, the number of the non-important local minima may increase exponentially with the parameter number due to the noise.

This method is not automatic and can extremely tedious if the number of the parameters is greater than even one. The concept of uniqueness of the solution is neither defined nor tested. Two complementary techniques were suggested to overcome these difficulties (SCHANZ REF): the concept the noise-free merit function and the concept of parameter elimination by sub-minimisation. The so resulted method is mathematically precise, the reliability is tested. This method was applied for the evaluation of the compression test data

\subsubsection{Notions}

Let us assume that the solution of the model for a real variable $v$ is the function $v(t, p)$, where $t$ is time, $\boldsymbol{p} \in R^{M}$ is parameter vector.

The sampling time vector $\boldsymbol{t} \in R^{\mathrm{N}}$ consists of the time values where data are sampled for the parameter identification. Its elements are $t^{j}(j=1 \ldots N)$. 
The simulated model response function $\boldsymbol{u}(\boldsymbol{p}): R^{\mathrm{M}} \rightarrow R^{\mathrm{N}}$ is defined for a specified sampling time vector $\boldsymbol{t}^{*}$. It is constructed in such a way that elements of the sampling time vector $\boldsymbol{t}^{*}$ are successively substituted for $t$ in the solution of the model $u(t, p)$, then the resulting $N$ functions $u\left(t^{j}, \boldsymbol{p}\right)(i=1 . . M),(\mathrm{j}=1 . . \mathrm{N})$ are assembled in vector $\boldsymbol{u}(\boldsymbol{p})_{\mathrm{i}} \in R^{\mathrm{N}}$. The (real-life) measured data vector $v_{\mathrm{m}} \in R^{\mathrm{N}}$ is a vector consisting of $N$ measured data $v_{\mathrm{m}, \mathrm{i}} \in R$. The error vector $\mathbf{h}_{\mathrm{m}}(\mathbf{p}): \mathrm{R}^{\mathrm{M}} \rightarrow \mathrm{R}^{\mathrm{N}}$ is a vector-vector function, the difference of the real-life measured data vector $\boldsymbol{u}_{\mathrm{m}}$ and the simulated model response vector $\boldsymbol{u}(\boldsymbol{p})$ :

The inverse problem is an unconditional minimisation:

$$
F(\boldsymbol{p})=\|\boldsymbol{h}(\boldsymbol{p})\|=\min !
$$

The applied merit function:

$$
F(\boldsymbol{p})=\frac{\sqrt{\sum_{i}\left[\left(v_{m}\left(t_{i}\right)-v\left(t_{i}, \boldsymbol{p}\right)\right]^{2}\right.}}{v_{m, \max } \sqrt{N}} 100[\%]
$$

\subsubsection{Noise-free approximation of the real-life merit function, minimisation}

The solution of the inverse problem is the global minimizer $\boldsymbol{p}_{\min }$ of the least squares objective (or merit) function which is related to the norm of the error vector $\boldsymbol{h}(t, \boldsymbol{p})=u_{\mathrm{m}}\left(t_{\mathrm{i}}\right)-u(t$, p). In the unweighted case:

$$
F(\boldsymbol{p})=\sum_{i=1}^{N}\left[u_{m}\left(t_{i}\right)-u\left(t_{i}, \boldsymbol{p}\right)\right]^{2}
$$

where $t_{\mathrm{i}}$ are the sampling times $(\mathrm{i}=1,2 . . N)$, subscript $m$ indicates the measured value and $\boldsymbol{p}$ is the parameter vector containing $M$ parameters which may influence (partly linearly and partly non-linearly) the solution $u(t, \boldsymbol{p})$ of the model. The so called follower merit function $F^{\prime}(\boldsymbol{p})$ is defined by the data simulated with $\boldsymbol{p}_{\text {min }}$ :

$$
F^{\prime}(\boldsymbol{p})=\sum_{i=1}^{N} h_{i}(\boldsymbol{p})^{2}=\sum_{i=1}^{N}\left[u\left(t_{i}, \boldsymbol{p}\right)-u\left(t_{i}, \boldsymbol{p}_{\min }\right)\right]^{2}
$$

The $z_{\mathrm{i}}$ is the noise can be expressed from the following decomposition:

$$
u_{m}\left(t_{i}\right)=u\left(t_{i}, \boldsymbol{p}_{\text {min }}\right)+z_{i}
$$

Using this, the two merit functions have the following relationship:

$$
F(\boldsymbol{p})=\sum_{i=1}^{N}\left[h_{i}(\boldsymbol{p})-z_{i}\right]^{2}=F^{\prime}(\boldsymbol{p})-\sum_{i=1}^{N}\left[2 h_{i}(\boldsymbol{p}) z_{i}\right]+F\left(\boldsymbol{p}_{\min }\right)
$$


If the noise is relatively small then the parameter domain has a part 'far' from the global minimum, where the two functions are similar. Where they are different, a geometric parameter error domain (13) is defined by the natural contour value $c$ of the follower merit function.

Having less critical points, it is worth minimizing the follower. This can be done far from the minima where the follower can be approximated by the real-life merit function ('similarity domain'), and, as a result, the non-important critical points can be skipped.

\subsubsection{Split inverse problem, the minimal section}

The parameter vector $\boldsymbol{p}$ is divided into two parts, $\boldsymbol{p}_{1}$ and $\boldsymbol{p}_{2}$ :

$$
\boldsymbol{p}=\left[\boldsymbol{p}_{1}, \boldsymbol{p}_{2}\right], \quad \boldsymbol{p}_{1} \in \mathfrak{R}^{J}, \boldsymbol{p}_{2} \in \mathfrak{R}^{M-J}
$$

The split or hierarchical inverse problem is as follows. The first inverse problem is a conditional minimisation for

$$
F\left(\boldsymbol{p}_{1}, \boldsymbol{p}_{2}\right)=\min !, \quad \boldsymbol{p}_{2}=\boldsymbol{p}_{2}^{*}
$$

The second

$$
F\left|\boldsymbol{a}\left(\boldsymbol{p}_{2}\right), \boldsymbol{p}_{2}\right|=\min !
$$

where the first subminimisation is made with respect to $\boldsymbol{p}_{1}$ and the second minimisation is made with respect to $\boldsymbol{p}_{2}$ such that the relation $\boldsymbol{p}_{1}=\boldsymbol{a}\left(\boldsymbol{p}_{2}\right)$ is determined beforehand:

The split inverse problem is equivalent to the original one if the Hessian matrix of the original objective function with respect to $\boldsymbol{p}=\left[\boldsymbol{p}_{2}, \boldsymbol{p}_{1}\right]$ is positive definite at least in the vicinity of the global minimum (which is assumed in this work). The statement follows from the fact that if the Hessian matrix with respect to $\boldsymbol{p}$ is positive definite then the Hessian matrix with respect to $\boldsymbol{p}_{1}$ and its Schur complement (i.e. the Hessian matrix for the first and second minimisations) are positive definite. This topologically means a non-degenerate minimum.

If the first sub-minimisation is solved on the whole domain of $\boldsymbol{p}_{2}$ pointwise then an $M-J$ dimensional section, the so called the minimal section of the merit function with respect to the parameter vector part $\boldsymbol{p}_{2}$ denoted by $F\left(\boldsymbol{a}\left(\boldsymbol{p}_{2}\right),\left(\boldsymbol{p}_{2}\right)\right)$, results and, the elimination of the parameter vector $\boldsymbol{p}_{1}$ occurs. If the model depends linearly on $\boldsymbol{p}_{1}$ then the pointwise solution can be found simply by the SVD algorithm in one minimisation step. If the model depends linearly on a part of $\boldsymbol{p}_{1}$ only, then the first sub-minimisation can be split also.

It can also be noted that - following from the definition - the one-dimensional minimal section of parameter $p^{\mathrm{i}}$, called the Critical Sensitivity Section (CSS) of $p_{\mathrm{i}}$, can be used for reliability testing as shown below. 


\subsection{Reliability tests by the minimal sections}

\subsubsection{Classical reliability tests}

The solution of the inverse problem is unique if (1) the global minimum of the noise-free merit function is single and is not degenerate, and if (2) the local minima of the follower noisefree merit function are not deeper than the minimum of the real-life merit function $F\left(p_{\min }\right)$. The solution of the inverse problem is precise enough if the parameter error domain (or confidence domain) of the solution is contained by the parameter domain ([4]).

Concerning the classical analytical methods, the local uniqueness condition is automatically tested if the standard deviation is computed from the covariance matrix ([4]). A "distribution free" $88 \%$ confidence interval is defined by the Chebychev inequality:

$$
P\left(\left|x_{i}-p_{i}\right| \geq a\right) \leq \frac{\sigma_{i}^{2}}{a^{2}}
$$

where $x_{i}$ is the expected value, and $\sigma_{i} \mathrm{~s}$ the standard deviation of parameter $p$.

\subsubsection{Reliability tests and regularization with critical sensitivity sections}

The reliability can be tested by the one-dimensional minimal section of a parameter $p_{\mathrm{i}}$, called the Critical Sensitivity Section (CSS) of $p^{\text {i }}$. Its projection onto the two dimensional space $F, p_{\mathrm{i}}$ is called the Critical Sensitivity Curve (CSC) of $p_{\mathrm{i}}$. Some properties of CSSs, by definition, are as follows.

The CSS of parameter $p^{\mathrm{i}}$ contains all important minima, therefore, it can be used for global uniqueness test. The point of the minimal section of parameter $p_{\mathrm{i}}$, where $p_{\mathrm{i}}=p_{\text {mini, }}$, is the global minimum $\boldsymbol{p}_{\min }$. As a result, the solution of an ill-posed inverse problem (with quasi-degenerate global minimum) can be approximated from the CSS of parameter $p_{\mathrm{i}}$, if the "good value" $p_{\operatorname{mini}}$ is known.

The intersection of the line $F\left(\boldsymbol{p}_{\min }\right)=$ constant and the CSS provides the size of the parameter error domain defined by a level line of the follower merit function in the direction of $p_{\mathrm{i}}$.

If the global minimum is quasi-degenerated on the minimal section for parameter $p_{i}$ but is not degenerated in the minimal section for any other parameter, then the solution of the inverse problem can be selected using some a priori information concerning the value of parameter $p_{i}$. The "steepness" of the vicinity of the global minimum of the CSS of parameter $p_{i}$ indicates the error for parameter $p_{i}(3,17)$. 